\title{
THE AUSTRALIAN EARTHWORM GENUS SPENCERIELLA AND DESCRIPTION OF TWO NEW GENERA (Megascolecidae: Oligochaeta)
}

\author{
By B. G. M. JAMIESON \\ University of Queensland
}

\begin{abstract}
A neotype is designated for a rediscovered specimen of Diporochaeta notabilis, the only known material of the type-species of Spenceriella Michaelsen. The genus appears to belong to a Dichogaster-Megascolides group of genera, though poor preservation precludes certain demonstration of the stomate median meronephridia diagnostic of the group. Specimens from Lord Howe Island are shown to merit recognition of a new genus and species, Paraplutellus insularis, closely allied to Heteroporodrilus Jamieson and Plutellus Perrier on the Australian mainland. The new genus Simsia is established to receive six Victorian species assignable in former classifications to Plutellus, including the new species Simsia longwarriensis. The typespecies $S$. tuberculata (Fletcher) is shown to be a senior synonym of Megascolides roseus Spencer. Paraplutellus and Simsia are members of a Perionyx group of genera.
\end{abstract}

\section{Introduction}

The author is currently studying the Baldwin Spencer earthworm collection through the kind co-operation of Dr B. J. Smith and the authorities of the National Museum of Victoria. Attention has initially been directed to resolving the heterogeneous and clearly polyphyletic assemblages Plutellus and Diporochaeta into distinct and individually more homogeneous groupings. This paper is confined to consideration of four species which in previous classifications would have been assignable to Plutellus or Diporochaeta but which represent three distinct genera of which two are new to science.

Diporochaeta notabilis Spencer, 1900, was made the type-species of a new genus Spenceriella by Michaelsen (1907). With D. notabilis were included the two Victorian species, D. maplestoni Spencer, 1900, and tentatively Perichaeta lateralis Spencer, 1892b, and also the two New Zealand species Diporochaeta gigantea Benham, 1906, and D. shakespeari Benham, 1906. S. shakespeari was shown by Lee (1962) to be a junior synonym of $S$. (for merly Megascolex) antarctica (Baird, 1871). Lee (1959) added two further species from New Zealand, $S$. argillae and $S$. pallida, bringing the generic total to seven species.

Michaelsen erected Spenceriella for species with more than eight setae per segment, one to three pairs of spermathecal pores, a gizzard in segment $\mathrm{V}$, meronephridia, and tubular prostate glands with unbranched lumen. This superficial definition (which ignored morphological heterogeneity in other respects) and the disjunct geographical distribution, has resulted in a polyphyletic genus. Revision of the genus and elucidation of the affinities of the included species necessitates examination of the typespecies. Jensz and Smith (1969) stated that the type specimens had presumably been lost and no other specimens of the species were known. The author has examined an unidentified perichaetine specimen from the type locality, Dimboola, Victoria, and finds it to be unequivocally identifiable as Spenceriella (= Diporochaeta) notabilis. As it is not possible to prove indisputably that it is part of the lost type series, and because of its significance for revision of the genus and for nomenclatural stability, it is here designated a neotype. This specimen is described below, and its significance discussed.

It has been shown (Jamieson 1970, 1971b) that the large circummundane genus Plutellus must be restricted to only two of the known species, Plutellus heteroporus Perrier, 1873, and Plutellus manifestus (Fletcher, 1889). Resolution of the remaining congeries has been commenced (Jamieson 1971a) by resurrection of Fletcherodrilus Michaelsen, 1891. In the present study a group of Victorian species which were formerly ascribable to Plutellus will be 
shown to warrant recognition as a distinct new genus.

A previously unidentified species from Lord Howe Island, assignable to Plutellus sensu Stephenson 1930, will be shown to represent a new monotypic genus allied to Heteroporodrilus Jamieson, 1970, and to Plutellus s. str.

\section{Systematics}

Genus Spenceriella Michaelsen, 1907

Spenceriella notabilis (Spencer, 1900)

Fig. 1 D-H.

Diporochaeta notabilis Spencer, 1900: 57-58, P1. 10, figs. 76-78.

Spenceriella notabilis; Michaelsen, 1907: 161.

$1=36 \mathrm{~mm}, \mathrm{w}$ (midclitellar) $=3 \mathrm{~mm}, \mathrm{~s}=$ 116. Form fairly stout, circular in transverse section throughout, lacking secondary annulation. Prostomium epilobous $3 / 4$ open and almost parallel-sided, the lateral margins perhaps continuous as faint grooves to intersegment $1 / 2$, i.e. possibly tanylobous. First dorsal pore $4 / 5$ (?), as noted by Spencer. Setae perichaetine commencing in II, the setal rings interrupted dorsally and ventrally in the midline except posteriorly where $b$ lines become irregular. Numbers of setae in XII: 11 (left), 11 (right); in XXV: 11 (left), 10 (right); at the posterior end 12 (left), 10 (right). Nephropores not externally visible. Clitellum poorly developed, annular, on XIV-XVI but intersegments $13 / 14$ and $16 / 17$, like those between, are faint, suggesting that when fully developed the clitellum would occupy at least part of XIII and XVII; dorsal pores, intersegmental furrows and setae retained. Male pores represented by a pair of indistinct papillae on XVIII approximately in $a$ lines. Accessory genital markings a pair of ellipitical dark glandular areas in X, $\mathrm{XIX}, \mathrm{XX}$ immediately lateral of $a$ lines, those in $\mathrm{X}$ and $\mathrm{XX}$ with depressed elliptical centres with narrow pale rims, possibly also represented on XVIII in $b$ line on the right side. Female pores minute orifices median and slightly anterior of setae $a$ of XIV in a common elliptical slightly tumid field. Spermathecal pores represented by a single pair of elliptical intersegmental markings in $7 / 8$, about as wide as $a b$ in which their centres lie very slightly median of $b$.

Septal thickening: $5 / 6$ and $6 / 7$ slight, $7 / 8$ and $8 / 9$ moderate, $9 / 10-12 / 13$ fairly strong, $13 / 14$ and $14 / 15$ slight, the remainder thin. Last pharyngeal glands in $\mathrm{V}$, overlying the gizzard. Dorsal blood vessel single, fragmented but apparently continuous onto the pharynx. Dorsoventral commissural vessels paired in VI-XII; those in X-XII forming rather narrow hearts, each of which is latero-oesophageal, arising from the dorsal vessel but also receiving a connective from a calciferous vessel where the latter joins a narrow supra-oesophageal vessel. The calciferous vessel circumscribes and receives vessels from the corresponding calciferous gland. Supra-oesophageal restricted to $\mathrm{X}$ XII. A latero-oesophageal vessel on each side supplies the calciferous glands. Gizzard large, firm and barrel shaped, in V. Calciferous glands four pairs, in X-XIII, each a large anteroposteriorly depressed lobe filling the space between the hearts and the oesophagus in X-XII and communicating with the oesophagus by the narrowed ventromedian portion of the gland, which forms a short duct; each gland with approximately 24 radial septa most of which unite centrally. Intestine commencing, with abrupt expansion and a narrow oesophageal valve, in XV. Typhlosole and muscular thickening absent.

Nephridia: meronephridia, not sufficiently well preserved to allow confirmation of Spencer's observation of pharyngeal nephridia. At the posterior end of the body preservation is generally inadequate for determination of nephridial morphology beyond recognition of several rows of meronephridia on each side but in one segment the nephridium nearest the nerve cord was observed to have a preseptal funnel. Testes and funnels not visible but holandry indicated by the presence of racemose seminal vesicles in IX and XII. Prostates racemose, bipartite with a small anterior and larger posterior lobe and short muscular duct; surface slightly lobulated; the exact form uncertain owing to partial fragmentation; no central lumen detectable in transverse serial sections. Ovaries (elongate wisps consisting of several chains of oocytes) and funnels in XIII. Spermathecae a single pair, in VIII; each with a sac-like ampulla approximately four times as long as wide, which is joined ectally, without the intervention of a 
separate duct, by a lateral digitiform diverticulum which is longer than the ampulla. Length of right spermatheca $=0.98 \mathrm{~mm}$; ratio of total length: length of diverticulum $=0 \cdot 7$.

Material examined: A single imperfectly clitellate specimen labelled only 'Dimboola, Victoria, Oct. 1892', Nat. Mus. Vict. G353, here designated a neotype.

Remarks: The above account considerably augments and closely accords with that of Spencer (1900). The only noteworthy departures of the newly examined material from Spencer's description are the racemose as opposed to tubular prostates and the intestinal origin in $\mathrm{XV}$ and not in XVI.

There is no evidence that Michaelsen examined specimens of Diporochaeta notabilis and his characterisation of the genus by tubular prostates presumably derived from Spencer's description of these glands as 'coiled, tubular'. Their lobular ('racemose') nature has been demonstrated above. Branching of the prostatic lumen renders Spenceriella indistinguishable from Megascolex as defined by Michaelsen (1907) but there is no reason to consider that $S$. notabilis is in fact congeneric with the typespecies of Megascolex, M. caeruleus Templeton, 1844, from Ceylon. Spenceriella is therefore retained. It is questionable, however, whether other species assigned to the genus are congeneric with the type species.

\section{Simsia* gen. nov.}

Prostomium variable, epilobous to tanylobous. First dorsal pore in or behind 4/5. Setae eight per segment, commencing on segment II, the rows sometimes becoming irregular posteriorly, ventral setal couples $(a b)$ wide (the median ventral interval $a a<3 a b$ ), dorsal setal couples ( $c d$ ) wider than $a b$ but much narrower than the distance $(b c)$ between the two setal couples, dorsal median intersetal distance $(d d)$ $0.3-0.5$ of the circumference $(u)$. Nephropores inconspicuous, or unrecognizable, in approximately straight series on each side in the vicinity of $c$ lines but those of the tufted nephridia typically further dorsally. Clitellum

* The genus is named after my friend and colleague, R. W. Sims, Curator of annelids, British Museum (Natural History). annular, not extending behind the male pores. A pair of combined male and prostatic pores on XVIII; the prostates thickly tubular, sometimes with lobulated surface; prostate duct muscular, lacking distinct ectal dilatation. Penial setae present or absent. Accessory genital markings present. Spermathecal pores two ventral pairs, segmental or at the anterior border of their segments, the posterior pair on IX.

Some preclitellar septa thickened. Gizzard well developed, in V. Oesophagus strongly dilated in XV and XVI to form two unpaired annular (calciferous?) glands, sometimes with lesser dilatation in XVII, intestine commencing in XVIII, XIX or XX; muscular thickening absent, lamelliform dorsal typhlosole present. Supra-oesophageal vessel present. Dorsal vessel single. Dorsoventral commissural vessels extending from the gizzard, or anterior to this, to XII; those in X-XII forming latero-oesophageal hearts, receiving connectives from the supraoesophageal and the dorsal vessel. Nephridia stomate, avesiculate holonephridia with the exception that those in a few anterior segments are tufted, meronephric (always?) and typically, at least, have composite ducts; the tufts sometimes preceded by one or two pairs of small holonephridia. Testes and funnels free in $\mathrm{X}$ and XI; seminal vesicles in IX and XII; or the first pair of testes, funnels and seminal vesicles reduced or absent. Ovaries and funnels in XIII. Ovisacs in XIV (not known in eucalypti). Spermathecae with saccular ampullae at the ectal limit of which is a sessile internally multiloculate subspherical diverticulum (In $S$. narrensis possibly shortly clavate and not known to be multiloculate); the duct long and coiled, or concealed in the body wall.

DIAGNOSIS: Nephridia stomate avesiculate holonephridia except in a few anterior segments which have tufted nephridia with (always?) composite ducts. Nephropores of holonephridia in a single series on each side. Unpaired annular (calciferous?) dilatations of the oesophagus in XV and XVI, XVII. Dorsal intestinal typhlosole present. Spermathecae two pairs, each with a small sessile internally multiloculate diverticulum.

DISTRIBUTION: Eastern Subregion, Koscius- 
kan Division, S. Southern Faunal Province of Kikkawa and Pearse (1969), in the vicinity of Warragul, Victoria, between lat. $145^{\circ}$ and $146^{\circ}$ S., long. $38^{\circ}$ and $39^{\circ} \mathrm{W}$.

TYPE SPECIES: Notoscolex tuberculatus Fletcher, 1888a. (syn. Megascolides roseus Spencer, 1892a)

\section{OTHER SPECIES:}

Megascolides eucalypti Spencer, 1900

Cryptodrilus intermedius Spencer, 1892

Simsia longwarriensis n. sp.

Megascolides manni Spencer, 1892

Cryptodrilus narrensis Spencer, 1892

The diagnosis indicates the striking morphological homogeneity of the species here included in Simsia. The phenetic unity of the group is unquestionable and, notwithstanding the acceptability of polythetic groups, future inclusion in the genus of species departing in one or more characters from the diagnosis would probably require recognition of separate subgenera if it were indeed justifiable.

Simsia differs from Plutellus s. str. in numerous respects, including the absence of stalked calciferous glands, of a complex alternation of nephropores, of nephridial bladders and in the presence of tufted (and apparently meronephric) nephridia and of a typhlosole. From the N. American species of Plutellus (other than the supposedly Pennsylvannian $P$. heteroporus) Simsia differs in the location of the oesophageal dilatations, presence of tufted nephridia and the more regular arrangement of nephropores. The $\mathrm{N}$. American species will have to assume the oldest available generic name, Argilophilus Eisen, after restriction of Plutellus to $P$. heteroporus (the type species) and $P$. manifestus.

The frequent alternation or irregularity of nephropores in Argilophilus, especially the regular alternation in $b$ and $d$ beginning with segment IX in Plutellus davisi MacNab and McKey-Fender, 1953, suggests affinity of $\mathrm{Argi-}$ lophilus with the Plutellus s. str.-Heteroporodrilus-Paraplutellus group of genera despite the presence of nephridial bladders in the latter group. On the other hand the general anatomy of Argilophilus is sufficiently close to indicate an affinity with Simsia closer than that with other megascolecoid genera despite separation of the two groups by the Pacific. The diversity of plutelloid genera in Australia, considered with the Pacific seaboard focus of endemicity of Argilophilus, perhaps suggests invasion of America from Australia or its vicinity. If this were by a Gondwanaland connection, the failure of Argilophilus to subsequently spread more widely in America is remarkable. The alternative of recent invasion across the Pacific (for instance by rafting or transportation) may be rejected in view of the diversity of species and evidence of subspeciation in America (MacNab and McKey-Fender 1960).

Simsia tuberculata (Fletcher, 1888)

Figs. 2 A-C, 3 A-B, E, H-I, L-N

Notoscolex tuberculatus Fletcher, 1888, pp. 611-614. Megascolides tuberculatus; Spencer, 1892a: 156; Beddard 1895 , p. 494.

Plutellus tuberculatus; Michaelsen, 1900, p. 168.

Megascolides roseus Spencer, 1892a, pp. 153-154, PI. 18 , figs. $58-60$, Pl. 19 , fig. 81 , Beddard 1895 , p. 491 , Sweet 1900 , p. 112.

$1=140 \mathrm{~mm}(160+\mathrm{mm}$ in the posterior amputee of $M$. roseus), w (segment XVIII tuberculatus, or midclitellar, roseus $)=7 \mathrm{~mm}$, $\mathrm{s}=165$ (tuberculatus), 88 (roseus). Circular in cross section throughout, posterior end clubbed, secondary annulation very distinct commencing in IV. Pigmentless buff in alcohol with the exception of the clitellum which is pigmented pale reddish brown. Prostomium epilobous $1 / 2$, or (roseus) pro-epilobous, but connected with intersegment $1 / 2$ by two longitudinal grooves which would confer a tanylobous condition on the prostomium were other longitudinal grooves not present on the peristomium. First dorsal pore 12/13. Setae indistinct, in eight regular longitudinal rows throughout, beginning on II; the ventral couples absent in XVIII.

Nephropores not externally visible (tuberculatus) or (roseus) visible in a single series on each side, in $c d$ nearer $c$, near the anterior borders of their segments, from IV posteriorly. Clitellum not developed in tuberculatus; in roseus annular, strongly protuberant, embracing the posterior $1 / 3$ XIII to the anterior $1 / 3$ XVIII but interrupted ventrally by the genital markings in XVII and XVIII; intersegmental 
TABLE 1

\section{INTERSETAL DISTANCES IN SEGMENT XII}

IN Simsia tuberculata

\begin{tabular}{|c|c|c|c|c|c|c|c|c|c|c|c|}
\hline \multirow[b]{3}{*}{$\begin{array}{l}\text { N. tuberculatus } \\
\text { intervals/ab }\end{array}$} & & \multicolumn{2}{|c|}{$a b$} & \multicolumn{2}{|c|}{ bc } & \multicolumn{2}{|c|}{ cd } & \multicolumn{2}{|c|}{ dd } & \multirow[t]{2}{*}{ dd:u } \\
\hline & $\mathrm{mm}$ & st & $\mathrm{mm}$ & st & $\mathrm{mm}$ & st & $\mathrm{mm}$ & st & $\mathrm{mm}$ & st & \\
\hline & $2 \cdot 21$ & $\begin{array}{r}13 \cdot 64 \\
3 \cdot 60\end{array}$ & 0.61 & $\begin{array}{l}3.79 \\
1.00\end{array}$ & $2 \cdot 33$ & $\begin{array}{r}14 \cdot 39 \\
3 \cdot 80\end{array}$ & 0.88 & $\begin{array}{l}5.41 \\
1.43\end{array}$ & 6.35 & $\begin{array}{l}39 \cdot 18 \\
10 \cdot 34\end{array}$ & 0.3 \\
\hline $\begin{array}{l}M . \text { roseus } \\
\text { intervals } / \mathrm{ab}\end{array}$ & $2 \cdot 29$ & $\begin{array}{r}12 \cdot 12 \\
3 \cdot 20\end{array}$ & 0.71 & $\begin{array}{l}3.79 \\
1.00\end{array}$ & 2.43 & $\begin{array}{r}12 \cdot 88 \\
3 \cdot 40\end{array}$ & 0.89 & $\begin{array}{l}4 \cdot 73 \\
1.25\end{array}$ & $8 \cdot 50$ & $\begin{array}{l}45 \cdot 08 \\
11 \cdot 90\end{array}$ & \\
\hline
\end{tabular}

* Standardized to a periphery of 100 .

furrows indicated, though weakly; setae and nephropores retained; dorsal pores absent. Male genital field: male pores a pair in XVIII, minute points in $a b$ (tuberculatus) or one in $b$ and the other lateral of $b$ (roseus), each on a small, low papilla; accessory genital markings consisting of a large median boss in XVIII between the male pores and paired markings with peripheral rim and raised central area the centre of which usually displays a pore or slit, located presetally in XVII and XX, XXI and XXII (tuberculatus) or XVII and XX only (roseus; observed in XVII, XX-XXIII by Spencer); the markings in XVII and XX in $a b$, those in XXI centred on $a$ lines and those in XXII with their centres slightly median of $a$ lines; the two presetal markings or each segment impinging slightly on the preceding segment and connected by a transverse glandular band. Female pores a pair in XIV, immediately in front of the setal arc and separated by about $1 / 3 a a$, both in a common glandular field. Spermathecal pores two pairs, located segmentally, in VIII and IX immediately in front of the setal arc shortly lateral of $a$ lines; each on a small elliptical papilla.

Septa: $3 / 4-5 / 6$ very thin, $5 / 6$ being displaced posteriorly by the gizzard; $6 / 7$ slightly (tuberculatus) to moderately strongly thickened (roseus), 7/8-12/13 strongly thickened, 9/10 being the thickest; 13/14-14/15 (roseus), $15 / 16$ (tuberculatus) slightly thickened; the remainder thin. Last septal (pharyngeal) glands anterior in IV. Dorsal blood vessel single, continuous onto the pharynx, dorsoventral commissurals in (IV?) V-XII; those in X-XII forming three pairs of large latero-oesophageal

hearts, each receiving a connective from the dorsal vessel and from a supra-oesophageal vessel. Supra-oesophageal present in VIII (?) (tuberculatus) - or IX (roseus)-XIII, seen in tuberculatus to be double in XI-XIII, and to receive in each of XII and XIII two pairs of large vessels running circumferentially on the oesophagus which is here vascularized though not widened. In XIV one pair of thick vessels from the vascular and dilated oesophagus joins the dorsal vessel and an indistinct anterior pair of oesophageal vessels probably feeds the supra-oesophageal vessels which abut on septum 13/14 (tuberculatus). Subneural vessel absent (both specimens). Large posteriorly running latero-parietals originating below the oesophagus in XIII (roseus).

Pharynx abutting posteriorly on septum $3 / 4$; a croplike muscular but compressible proventriculus in IV; gizzard large, firmly muscular, elongate-globose in $\mathrm{V}$ (septum $5 / 6$ so attenuated over the gizzard as to be almost unrecognizable). Oesophagus narrow to XIV, greatly dilated and strongly vascularized in XV and XVI to form two unpaired annular calciferous (?) glands each of which gives two pairs of vessels to the dorsal blood vessel, the dilatations thin walled, with internally low longitudinal vascular folds surrounding the capacious oesophageal lumen; the glands not constricted off or separated from the oesophagus. Oesophagus wide and vascularized throughout XVII, though narrower than in XVI, the intestine commencing in XVIII (both specimens). Intestine lacking muscular thickening but with a thickly laminar dorsal typhlosole commencing in segment XXIX-XXX. 


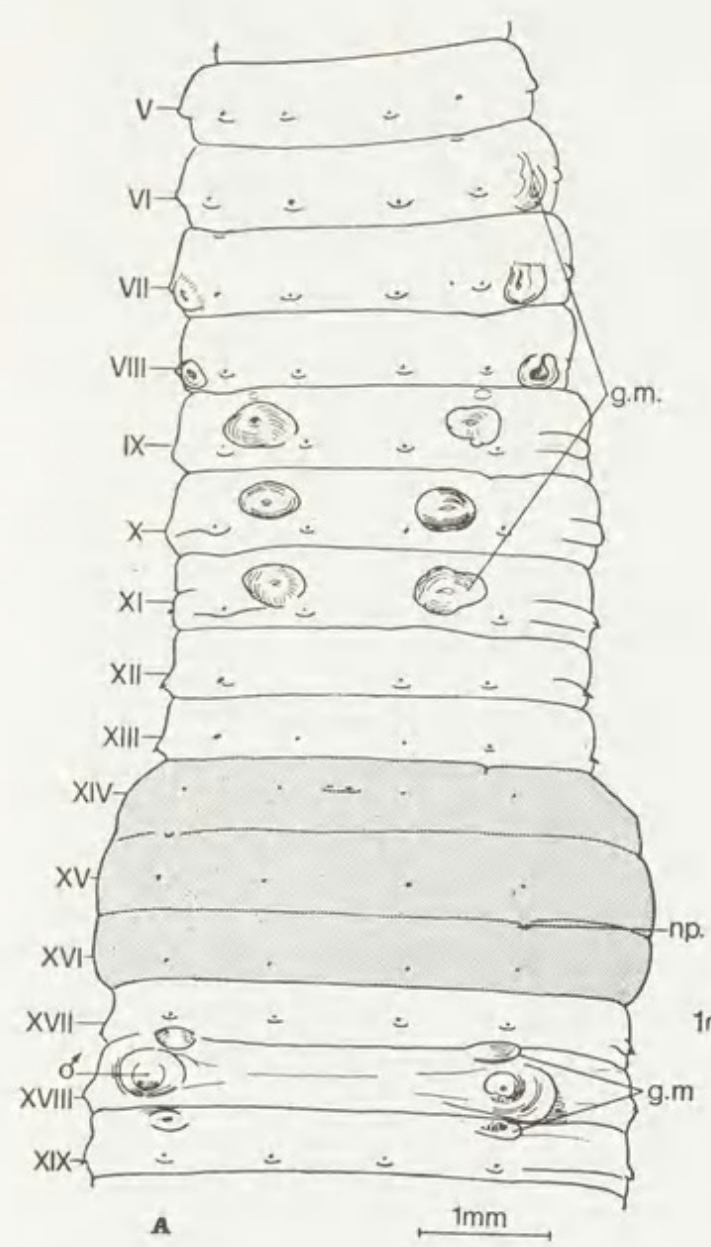

A
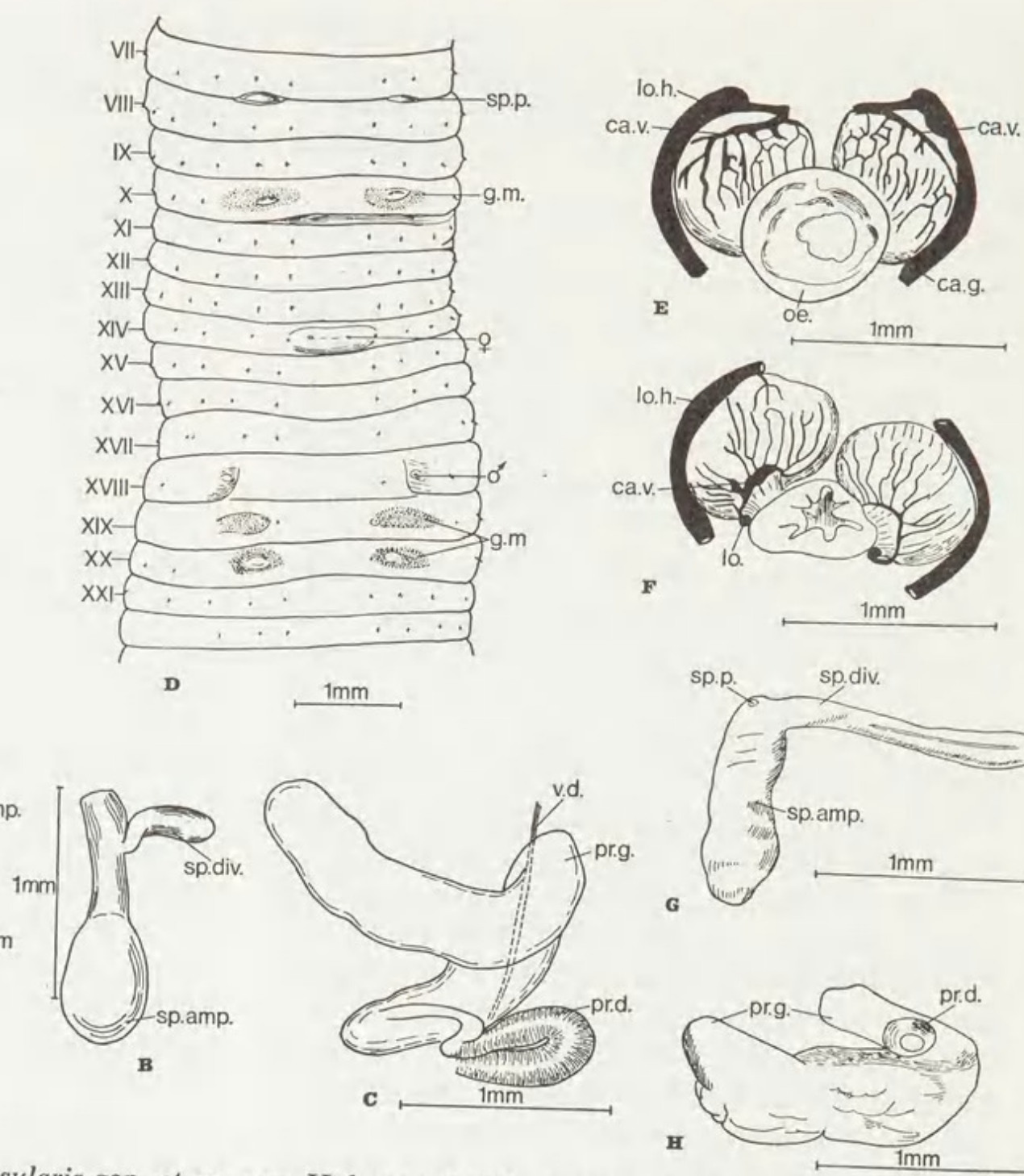

Fig. 1-A-C, Paraplutellus insularis gen. et sp. nov. Holotype G416. A, ventral view of genital fields. B, right spermatheca of segment IX. C, right prostate gland. D-H, Spenceriella aspects respectively of the calciferous view of genital fields. E-F, anterior and posterior ventral aspect of right prostate; part of the ands of X. G, right spermatheca of VIII. H, All by camera lucida. Clitellum shaded.

Nephridia not observable in II, in III nephridia small exonephric holonephridia, those in IV, V and VI paired (stomate?) exonephric tufted nephridia with composite ducts and approximately six loops in IV, 20 loops in V and 40 loops in VI, those in VII much coiled but each with a simple duct. The ducts of the nephridia of IV discharge anteriorly in III while those of the nephridia of V and VI discharge anteriorly in their respective segments. Nephridia in VIII and succeeding segments stomate, exonephric, avesiculate holonophridia; all pre-intestinal nephridia considerably coiled; intestinal nephridia not coiled; those of the last 20 segments (approximately) thicker than the preceding nephridia, and with larger funnels, but with no other variation from the usual form (tuberculatus) (Horan pers. comm.). Nephridia in roseus similar (personal observations).

Small testes and large, convoluted iridescent sperm funnels free in X and XI; racemose seminal vesicles in IX and XII. Prostates much coiled, the coils with flattened faces and closely adpressed; limited to segment XVIII which they expand longitudinally or in roseus extending into XIX; the relatively short duct slender and twisted; the two vasa deferentia of a side completely separate, joining the glandular portion of the corresponding prostate shortly ental 
of the duct. Penial setae slender, ectally slightly curved, the tip pointed in profile but fairly broad when viewed from above; the ectal region bearing scattered cicatricing; lengths of two setae 0.95 and $1.2 \mathrm{~mm}$, width of the shafts at the ectal fourth $20 \mu$ (tuberculatus). In roseus the penial setae are closely similar; the cicatricing of the ectal sixth consists of a series of several notches each of which corresponds with an irregular transverse serration encircling half or less of the circumference of the seta; length of a mature seta $1.05 \mathrm{~mm}$, width shaft $20 \mu$. Bushy ovaries (with many strings of large oocytes) and delicate pleated funnels in XIII; ovisacs present on the anterior face of XIV (roseus).

Spermathecae each wih a large saccular ampulla and well demarcated, narrow, tortuous, muscular duct which extended approximately equals the ampulla in length, and a subspherical somewhat lobulated diverticulum sessile on the duct shortly ectal of the ampulla. Uniform in size, in IX (right side) length extended $=4 \cdot 3$ $\mathrm{mm}$, ratio total length: length duct $=2 \cdot 1$, ratio total length: length diverticulum $=9.4$ (tuberculatus).

Material examined: A mature but aclitellate undissected specimen labelled 'Megascolides tuberculatus Fletcher. Jar 5', Nat. Mus. Vict. G172, probably part of the type series which is missing from the Australian Museum; here designated a lectotype. An aclitellate undissected specimen labelled (apparently in Spencer's writing) 'Megascolides roseus', Victoria, and curatorially 'Plutellus roseus', Australian Museum Sydney W1278, probably part of the type series which Jensz and Smith (1969) were unable to locate in the National Museum of Victoria.
Simsia intermedia (Spencer, 1892)

Fig. 2E, 3F-G, K.

Cryptodrilus intermedius Spencer, 1892a, pp, 133-134, Pl. 14, figs. 4-6, Pl. 19, fig. 64.

Cryptodrilus intermedius, Beddard 1895, p. 492.

Plutellus intermedius, Michaelsen 1900, p. 170.

Megascolides intermedius, Sweet 1900, pp. 110-111.

$1=98,220$ and $105 \mathrm{~mm}, \mathrm{w}$ (midclitellar)

$=5,5$ and $4 \mathrm{~mm}, \mathrm{~s}=172,175$ and 178 (G58, G86 and G1406 respectively). Form moderately slender, posteriorly clubbed, segments of the forebody at first biannulate, and subsequently triannulate to quadriannulate. Pigmentless buff in alcohol. Prostomium epilobous < $1 / 3$ closed (G86 and G1406; indeterminable in G58). First dorsal pore $4 / 5$ (imperforate G1406), or $5 / 6$ (G58, G86, perforate as in G1406). Setae eight per segment, commencing on II, all rows except $a$ irregular at the posterior end; $a b$ absent, $c d$ present, in XVIII; individual setae sporadically displaced in some anterior segments in some specimens.

Nephropores not externally visible (G58, G1406) or visible in $c$ lines (G86). Clitellum not developed (G58, G1406) or well developed, annular, on the posterior $1 / 3$ XIII to anterior 1/3 XVIII; nephropores, dorsal pores, setae and intersegmental furrows retained. Male pores minute slits on dome-shaped papillae in $a b$ of XVIII, both surrounded by a median tumescent genital marking which extends from $1 / 4 \mathrm{XVII}$ to $1 / 3 \mathrm{XX}(\mathrm{G} 86)$ or to $2 / 3 \mathrm{XX}$ (G58, G1406) and slightly above $b$ in XVII, XVIII and XIX and barely reaching $a$ or $b$ in $X X$. Intersegmental furrows and secondary annulation continuous across the genital marking though weak when this is well developed. Female pores minute transverse slits median to and slightly anterior to setae $a$ of XIV, on the anterior region of the setal annulus. Spermathecal pores on two pairs of small hemis-

TABLE 2

\section{INTERSETAL DISTANCES IN SEGMENT XII IN}

\section{Simsia intermedia}

\begin{tabular}{|c|c|c|c|c|c|c|c|c|c|c|c|}
\hline & \multicolumn{2}{|c|}{ aa } & \multicolumn{2}{|c|}{$a b$} & \multicolumn{2}{|c|}{$b c$} & \multicolumn{2}{|c|}{$\mathrm{cd}$} & \multicolumn{2}{|c|}{ dd } & \multirow[t]{2}{*}{ dd:u } \\
\hline & $\mathrm{mm}$ & st & $\mathrm{mm}$ & st & $\mathrm{mm}$ & st & $\mathrm{mm}$ & st & $\mathrm{mm}$ & st & \\
\hline G58 & $1 \cdot 29$ & 9.82 & 0.57 & $4 \cdot 34$ & 1.79 & $13 \cdot 60$ & 0.71 & $5 \cdot 41$ & 5.71 & 43.49 & 0.43 \\
\hline & 1.29 & $10 \cdot 69$ & $0 \cdot 50$ & $4 \cdot 14$ & 1.50 & $12 \cdot 43$ & 0.54 & 4.47 & 5.71 & $47 \cdot 31$ & 0.47 \\
\hline If & 1.29 & 9.71 & 0.64 & $4 \cdot 82$ & 1.50 & 11.29 & 0.79 & 5.94 & $6 \cdot 14$ & $46 \cdot 20$ & 0.46 \\
\hline C & 1.29 & $10 \cdot 62$ & 0.50 & $4 \cdot 12$ & 1.57 & 12.93 & 0.64 & $5 \cdot 27$ & 5.43 & 44.73 & 0 \\
\hline st. & & $10 \cdot 21$ & & $4 \cdot 36$ & & $12 \cdot 56$ & & $5 \cdot 27$ & & $45 \cdot 43$ & 5 \\
\hline $\mathrm{an} / \mathrm{ab}$ & & $2 \cdot 34$ & & 1.00 & & 2.88 & & $1 \cdot 21$ & & $10 \cdot 42$ & \\
\hline
\end{tabular}


pheroidal papillae at the anterior borders of segments VIII and IX but displaced into intersegments $7 / 8$ and $8 / 9$ in $a$ lines; the preceding setal annulus slightly bowed anteriorly in their vicinity (all examined specimens).

Internal anatomy (G1406, G86). Septal thickening: $5 / 6$ extremely thin; $6 / 7-12 / 13$ very strong, $6 / 7$ and $12 / 13$ less strong than the others; $13 / 14$ moderate; $14 / 15$ and $15 / 16$ slightly thickened. Last pharyngeal glands anterior in IV. Dorsal blood vessel single. Dorsoventral commissural vessels in VI-XII; those in VI-IX originating only from the dorsal vessel; those in X-XII forming large latero-oesophageal hearts arising from the supra-oesophageal vessel and from the dorsal vessel. Supra-oesophageal vessel in VIII-XIII. Subneural vessel (?). Gizzard large, barrel shaped, strongly muscular though fairly easily compressible, in V; preceded in IV by a muscular compressible proventriculus (crop) which is gizzardlike in appearance. Oesophagus not evidently vascularized in VI and VII; from VIII-XIV moniliform and with circumferential vascular striae; in XV and XVI greatly widened and vascularized giving in each segment two pairs of large vessels to the dorsal vessel and conspicuously visible on opening the animal whereas the preceding region of the oesophagus is concealed in thick funnel shaped septa; the internal walls of these dilatations covered by innumerable large rounded villi; oesophagus in XVII similarly dilated in its anterior half but narrow in the posterior half and in XVIII. Intestine commencing in XIX with abrupt expansion; muscular thickening absent; a deep dorsal typhlosole present, commencing at approximately segment XXVI (G1406, G86).

Nephridia exonephric holonephridia throughout with the exception of those in II, III and IV which form exonephric meronephric tufts with composite ducts; those in V-VII large and coiled but with simple ducts; preseptal funnels demonstrated for nephridia of VIII posteriorly but septal connectives (necks of nephrostomes?) observed from segment II; bladders absent (G1406-Horan pers. comm.).

Moderately large iridescent sperm funnels in $\mathrm{XI}$, very small non-iridescent funnels in X, racemose seminal vesicles in XII only
(G1406), the anterior sperm funnels absent in G86. Prostates short tortuous tubes with adpressed coils of irregular cross section, in XVIII and XIX; each with a very short muscular duct the surface of the gland in G1406 minutely and copiously lobulated. Penial setae absent, unpaired glandular masses present medianly and partly obscuring the prostate ducts, correspond with the external genital markings. Ovaries (large, palmate, with many terminal chains of large oocytes) and funnels in XIII, ovisacs present in XIV. Spermathecae two pairs, uniform in size, discharging anteriorly in their segment; the ampulla elongate-ovoid, about four times as long as wide, almost sessile on the body wall, there being virtually no extramural spermathecal duct; a large subspherical but dorsoventrally depressed multioculate iridescent diverticulum present at the ectal end, and as wide as the ectal end of the ampulla (G1406, G86). Length of the anterior spermathecae of VIII $=2.3 \mathrm{~mm}$; ratio length spermatheca: length diverticulum $=8.5$ (G1406).

Material examined: From S. Warragul, Vict., coll. W. Mann, July 1891: Nat. Mus. Vict. G58 (one aclitellate specimen); G1406 (six aclitellate specimens of which one was used for the above description); July 1892, G86 (four clitellate and six aclitellate specimens plus fragments). Locality unknown, G72 (two much dissected clitellate specimens).

Remarks: G58 was designated the lectotype and G1406 paralectotypes by Jensz and Smith (1969). G58 and four of G1406 have male genital fields which agree closely with the above description, while one has a weakly developed field which is not certainly identifiable and the sixth lacks a field. Specimens of both species differ from the type description (Spencer 1892a) in being aclitellate and in being shorter than the seven inches given by Spencer. A label with G58 in Spencer's writing reads 'Young of C. intermedius'. Designation of G58 as lectotype and of G1406 (from the same original series) as paralectotypes is therefore invalid.

The series G86, consisting of clitellate specimens which conform in size and anatomy with Spencer's account and which are referred to in Spencer's manuscript notes as 'MSS', would 

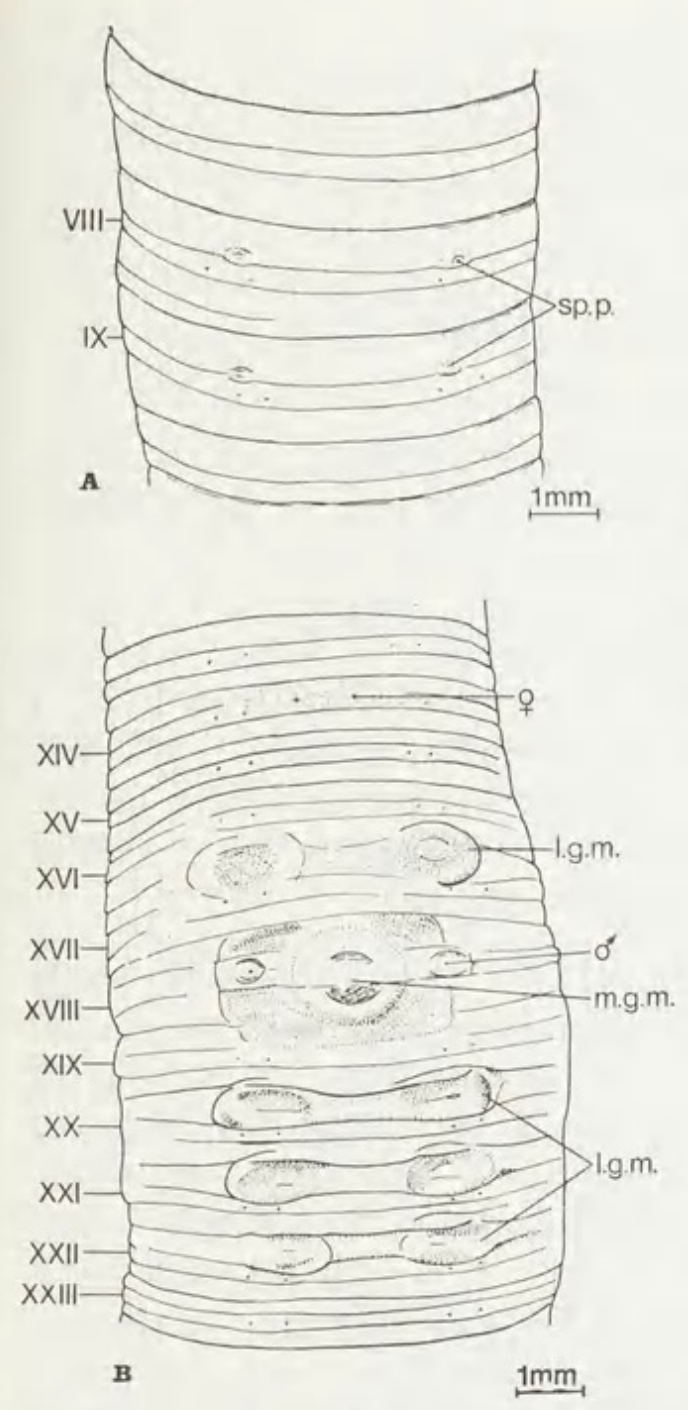
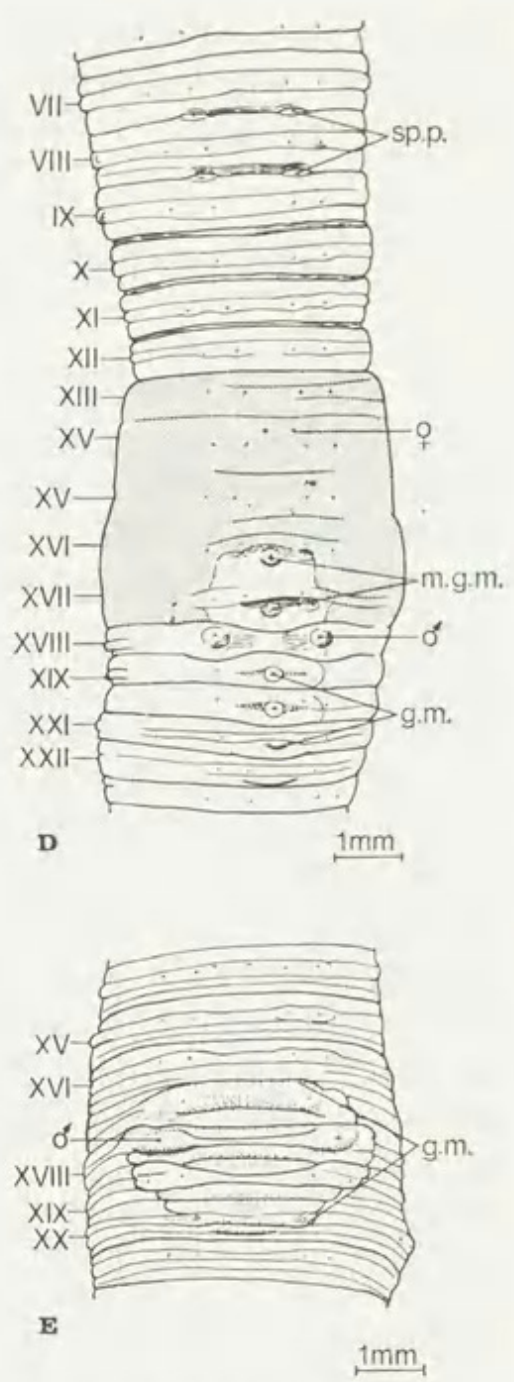

Fig. 2-A-C, Simsia tuberculata lectotype G172. A, spermathecal pores. B, male genital field. C, junior synonym Megascolides roseus W1278, ventral view of genital fields. D, Simsia longwarriensis n. sp. Holotype, ventral view of genital fields. E, Simsia intermedia paralectotype G58, male genital field.

All by camera lucida. Clitellum shaded.

appear to be the type series. The series cannot at present be considered lectotypic, however, as a museum label gives the data 'South Warragul, July 1892 ', post-dating the type description. It is nevertheless probable that the date is an error of transcription for July 1891 .

A specimen of $\mathrm{G} 72$ has been examined externally and agrees closely with the above description. Only its intersetal ratios have, however, been included therein. This material would not appear to be part of the type series as it includes a label in Spencer's hand which reads 'C. intermedius (?) two different forms? .... .', the remainder being only partly legible. There are two further specimens of $C$. intermedius in the Australian Museum (W1284) which have not been seen by the author. These were identified by Spencer and are possibly part of the type series, although not so designated.

\section{Simsia longwarriensis n. sp.}

Fig. 2D, 3C-D, J.

$1=62 \mathrm{~mm}, \mathrm{w}$ (midclitellar) $=4.6 \mathrm{~mm}$, $s=129$. Pigmentless, buff in alcohol. Form moderately stout, circular in cross section throughout, the posterior end clubbed. Prostomium very wide, parallel-sided, tanylobous; not canaliculate; the peristomium short. First dorsal pore $11 / 12$. Setae in eight regular longitudinal lines throughout, commencing on II; setae $a b$ absent, $b c$ present in XVIII. 
TABLE 3

\section{INTERSETAL DISTANCES IN SEGMENT XII}

\section{IN Simsia longwarriensis (holotype)}

\begin{tabular}{cccccccccccc} 
& \multicolumn{2}{c}{ aa } & \multicolumn{2}{c}{ ab } & \multicolumn{2}{c}{ bc } & \multicolumn{2}{c}{ cd } & \multicolumn{2}{c}{ dd } & dd:u \\
& $\mathrm{mm}^{\mathrm{st}}$ & $\mathrm{mm}$ & st & $\mathrm{mm}$ & st & $\mathrm{mm}$ & st & mm & st & \\
& 0.88 & 8.19 & 0.50 & 4.59 & 1.53 & 14.26 & 0.95 & 8.85 & 3.9 & 36.39 & \\
intervals/ab & & 1.79 & & 1.00 & & 3.10 & & 1.92 & & 7.93 & 0.36
\end{tabular}

Nephropores not externally visible. Clitellum annular, moderately protuberant; embracing XIII-XVII and dorsally $1 / 3$ XVIII, paler (and weaker?) ventrally between setae $b$ of XVI and XVII. Male genital field, a pair of small male porophores in $b$ lines and equatorial in XVIII; median genital markings consisting of single, median circular papillae each with a central pore, equatorial in each of segments XVI, XVII, XIX-XXI, and a slight corresponding tumescence in XXII. A suggestion of paired markings in XVI and XVII behind setae $a$. Female pores minute, anteromedian to setae $a$ of XIV (seen on right only). Spermathecal pores 2 pairs of conspicuous ellipses in $a$ lines, in $7 / 8$ and $8 / 9$.

Septa: $3 / 4-7 / 8$ thin; $8 / 9$ moderately thickened; $9 / 10-13 / 14$ fairly strongly thickened, the thickness increasing to $11 / 12$ and then decreasing; the remainder thin. Pharyngeal glands large lobes excepting the last which are small masses in IV (?). Dorsal blood vessel single, very narrow at the pharynx. Dorsoventral commissural vessels in IV (ventral connection verified) to XII; those in IV-XI slender, though increasing in thickness posteriorly; those in X-XII forming large latero-oesophageal hearts, each receiving a connective from the dorsal vessel and from a supra-oesophageal vessel where this receives a pair of circum-oesophageal intramural vessels. Supra-oesophageal vessel single, in X-XII and receiving a pair of vessels posteriorly from circum-oesophageal intramural vessels in XIII. Subneural vessel absent.

Gizzard large, globose and strongly muscular in $\mathrm{V}$ (septum 5/6 so attenuated as to be almost unrecognizable); proventriculus absent. Oesophagus supressed by backward extension of the gizzard in VI and VII; narrow in VIII; moniliform and vascularized, though narrow, in IX$\mathrm{XIV}$; greatly expanded in XV and XVI to form

two annular (calciferous?) glands; the walls of each gland thrown into numerous ridges, which end freely in the cavity of the gland; the glands not subdivided from the narrow oesophageal lumen. Oesophagus narrow in XVII; intestine beginning, with abrupt expansion, in XVIII; a very large thickly laminar dorsal typhlosole present, filling almost the entire height of the intestinal lumen, commencing in XXI; muscular thickening and caeca absent.

Nephridia in VI, posteriorly, stomate avesiculate holonephridia with preseptal funnels, the slender ectal ducts penetrating the parietes in $c$ lines. Large tufted nephridia consisting of many spiral loops in $V$ anteriorly, the entire mass apparently discharging by a single (composite?) duct on each side well above $d$ lines, at intersegment $2 / 3(1 / 2$ ?). Testes, non-iridescent funnels and copious free sperm masses in $\mathrm{X}$ and $\mathrm{XI}$; seminal vescicles elongate, strongly racemose, in IX and XII. Prostates restricted to an enlarged segment XVIII; tubular and very tortuous, the folds lobulated, adpressed and flattened in contact so that the gland is compacted into a single mass which bears a superficial resemblance to a racemose prostate and, from its lobulation and the irregularity of the cross section, may be considered intermediate in form between the tubular and racemose types. Vasa deferentia joining the gland shortly ental of its junction with the muscular duct which is looped once. Penial setae absent. Accessory genital markings represented internally by villous median glandular masses in XVIXXI. Ovaries bushy masses in XIII together with small funnels; ovisacs large laminae, with several chains of large oocytes in XIV well above the oviducal funnels on the anterior septum of XIV. Spermathecae two pairs, relatively very large, the anterior pair reflexed into VII, each with an ovoid ampulla and a narrow coiled 
almost equally long duct, a multiloculate sessile iridescent diverticulum attached to the junction of ampulla and duct. Posterior spermathecae larger than the anterior. Length of right spermatheca of IX (extended) $=4.3 \mathrm{~mm}$, ratio total length spermatheca: length duct $=2 \cdot 2$, ratio total length: length diverticulum $=18.6$.

Material examined: A single specimen, here designated the holotype, Longwarry S. via Drouin, Vict., coll. J. T. Ryan, 14 Aug. 1904, Nat. Mus. Vict. G1552.

\section{Paraplutellus gen. nov.}

Prostomium tanylobous. Dorsal pores present. Setae eight per segment, in regular longitudinal rows, commencing on II; ventral setal couples $(a b)$ wide, dorsal setal couples $(c d)$ at least twice as wide, and wider than the intervening distance $(b c)$; dorsal median setal distance $(d d) 0.2$ of the circumference $(u)$. Nephropores large, first in $d$ lines (segments IIIV); then in $c$ lines for one or two segments; thereafter alternating between $d$ and $b$ lines. Clitellum annular, on XIV-XVI. A pair of combined male and prostatic pores on XVIII in $b$ lines: the prostates with thickly tubular glands and muscular, ectally dilated ducts. Penial setae and accessory genital markings present. Spermathecal pores five pairs, the last at the anterior margin of IX.

Some preclitellar septa thickened. Gizzards absent. A pair of sessile extramural calciferous glands in XIII; intestine commencing in XVI; muscular thickening and typhlosole absent. Supra-oesophageal vessel present. Dorsoventral commissural vessels in VI-XII; those in X-XII forming large latero-oesophageal hearts which receive connectives from the supra-oesophageal vessel and from the dorsal vessel. Nephridia stomate holonephridia; the duct of each with a large diverticulate ectal bladder. Testes and funnels free in $\mathrm{X}$ and $\mathrm{XI}$; seminal vesicles in IX and XII. Ovaries and funnels in XIII; ovisacs absent. Spermathecae discharging anteriorly in their segments; each with a single diverticulum.

DIAGNOSIS: Holonephric with large nephridial bladders; nephropores in a few anterior segments in $d$ lines, then in $c$ lines, and thereafter (from VI or VII) alternating from $d$ to $b$ lines. Sessile calciferous glands present. Combined pores of a pair of (tubular) prostates and the vasa deferentia in XVIII.

DISTRIBUTION: Lord Howe Island, 1t. $31^{\circ}$ $31^{\prime}$ S., long., $159^{\circ} 04^{\prime}$ : E.

TYPE SPECIES: Paraplutellus insularis n. sp. Remarks: Lord Howe Island is $700 \mathrm{~km}$. NE. of Sydney, Australia, but is a true oceanic island separated from the mainland by the Tasman Abyssal Plain at a depth of $4,900 \mathrm{~m}$. It lies on a rise which is covered by about $1,200 \mathrm{~m}$. of water and which joins the Coral Sea Platform in the N. and the S. Island of New Zealand in the South. It is largely volcanic, with lavas considered to be of Pliocene to Pleistocene age but even with the post-glacial rise in sea level much of the island remained exposed (Standard 1967) and therefore the terrestrial fauna may date at least from the Pleistocene and possibly from an earlier period. Endemicity of Paraplutellus on this isolated island is, however, questionable and the possibility of introduction from E. Australia, where its near relatives Plutellus manifestus and Heteroporodrilus are endemic, cannot be dismissed.

Paraplutellus forms with Plutellus s. str. (Jamieson 1971b) and Heteroporodrilus Jamieson (1970) a highly distinct group characterized by a more or less complex alternation of nephropores on each side of the body and presence of very large subspherical nephridial vesicles. The alternation of nephropores in Paraplutellus is distinctive of the genus and yet is intermediate between the arrangements in the other two genera. Like Heteroporodrilus, the pores lie in $d$ lines in segments II-IV or V and then in $c$ lines for a few segments but whereas in Heteroporodrilus alternation from $b$ to $d$ lines commences within one or two segments of X, it commences in VI or VII in Paraplutellus as in Plutellus s. str. In the latter genus the pores in $\mathrm{V}$ or VI anteriorly are in $c$ lines only.

Paraplutellus also resembles Plutellus in possessing tubular prostates (these glands are racemose in Heteroporodrilus) and in the ectal dilatation of their ducts.

Setal ratios are closely similar in the three genera; the ventral setae $(a b)$ are widely paired 


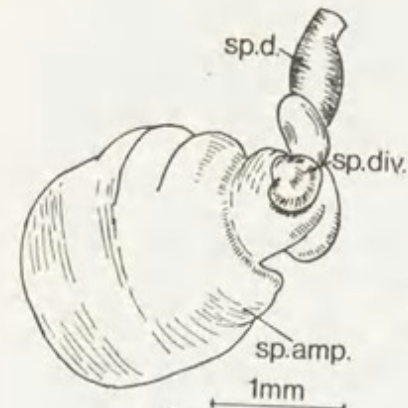

$\mathbf{A}$
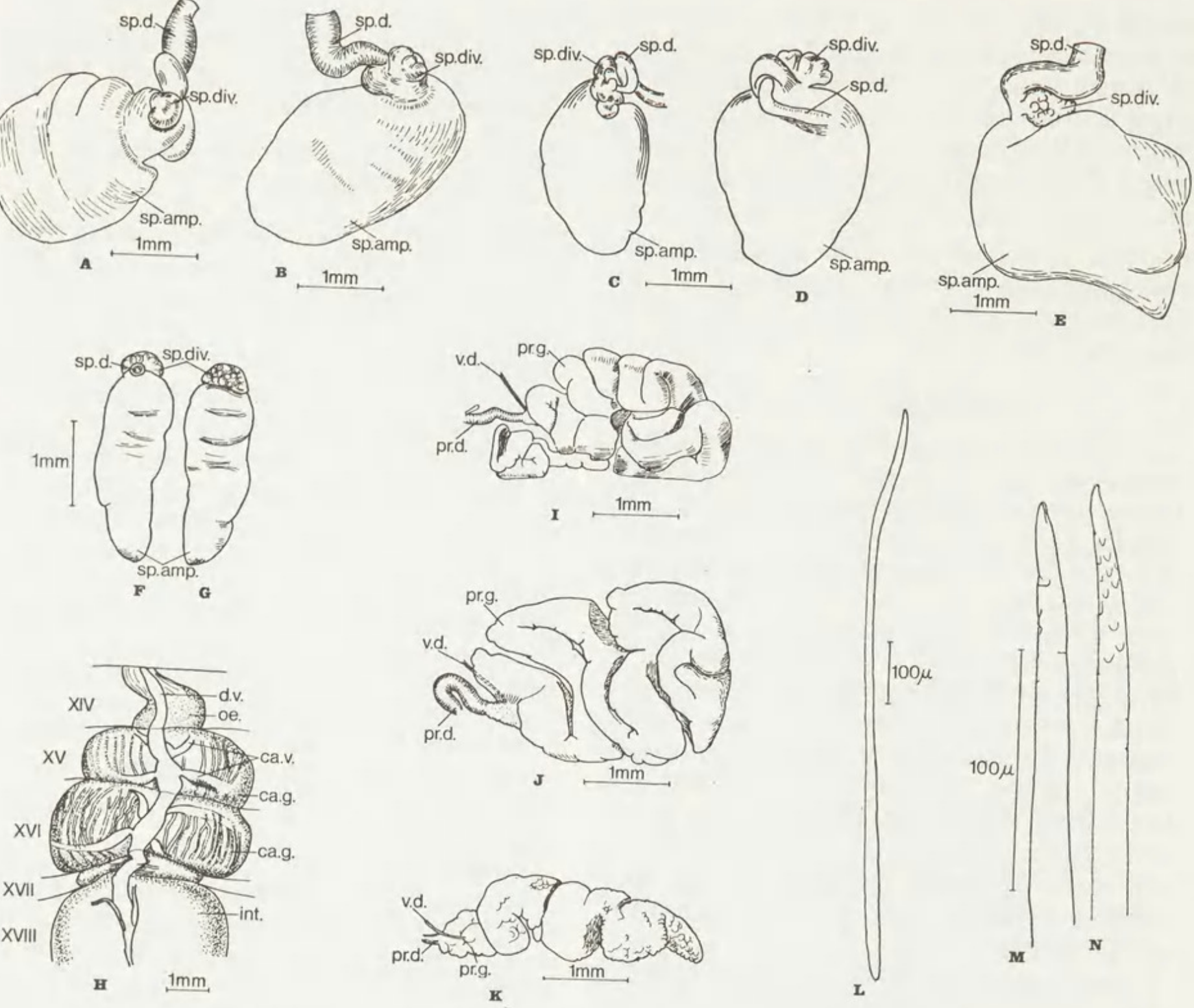

Fig. 3-A-B, Simsia tuberculata lectotype G172 left and right spermathecae of IX. C-D, Simsia longwarriensis n. sp. right spermatheca of VIII and IX. E, Simsia tuberculata (junior synonym Megascolides roseus W1728) right spermatheca of IX. F-G, Simsia intermedia tuberculata (junior synonym dorsal aspects of right spermatheca of VIII. H, Simsia right prostate glands of the a Mascolides roseus W1728) califerous glands. I-K, longwarriensis and K, Simsia intermedia. I, Simsia tuberculata G172, J. Simsia seta. M, tip of same. N, tip of further penial, Simsia tuberculata G172. L, penial All by camera lucida.

or distant and the dorsal setae $(c d)$ are more widely separated, the interval between them being greater than or only slightly smaller than the interval $(b c)$ between the two setal couples; the dorsal median intersetal distance $(d d)$ is only $0 \cdot 2-0 \cdot 3$ of the body circumference (all ratios in segment XII).

Paraplutellus differs from the other two genera in having calciferous glands in XIII only (in IX-X or XI-XIII in Heteroporodrilus, XXIII in Plutellus) and in the absence of a gizzard. Individuals of Heteroporodrilus tryoni are known in which the gizzard is rudimentary but the difference in arrangement and form of the calciferous glands in both Heteroporodrilus and Plutellus, together with the peculiar arrangement of the nephoropores in each, leaves no doubt that Paraplutellus is distinct. 
Paraplutellus insularis n. sp.

Fig. 1A-C.

$1=28$ (paratype) and $46 \mathrm{~mm}$ (holotype), $\mathrm{w}$ (midclitellar) $=4.5 \mathrm{~mm}, \mathrm{~s}=68$ (posterior regenerate) and 98. Form moderately stout, circular in cross section throughout, setal annuli moderately prominent but distinct secondary annulation lacking. Pigmentless buff in alcohol. Prostomium tanylobous, with very narrow, almost parallel-sided dorsal tongue; not canaliculate. First dorsal pore $6 / 7$, setae in eight regular longitudinal rows, commencing on II; $a b$ absent, $b c$ present, in XVIII.

Nephropores sporadically visible externally, anterior in their segments in more than one series on each side, from internal distribution of vesicles in $d$ lines in segments II-IV, in $c$ lines in $\mathrm{V}$ or in $\mathrm{V}$ and VI, alternating from $b$ to $d$ lines in successive segment from VI or VII posteriorly.

Clitellum annular and very strongly protuberant as a conspicuous narrow band around the body, embracing XIV-XVI; dorsal pores, nephropores, setae and intersegmental furrows retained. Male genital field: male pores on XVIII in $b$ lines on large, prominent porophores which extend from 1/3 XVIII-18/19. Very small eye-like accessory genital markings in $b$ lines, a pair anteriorly in XVIII impinging on intersegmental furrow $17 / 18$ and a pair anteriorly in XIX, impinging slightly on furrow $18 / 19$. Further accessory genital markings large paired oval glandular areas with depressed centres, occupying the posterior halves of segments VI, VII and VIII in $b c$ (that in VI not represented on the right side); in IX in front of setae $b$, and in X and XI presetally in $a b$ (holotype). In the paratype the male porophores are similar, but only the accessory genital markings in XVIII and XIX are present. Female pores a pair in XIV, very near the midventral line immediately in front of the setal arc. Spermathecal pores inconspicuous, five pairs, in $4 / 5-8 / 9$, in $c$ lines.

Septal thickening: $3 / 4-6 / 7$ thin, $7 / 8-8 / 9$ slightly, 9/10-14/15 moderately, $15 / 16$ slightly thickened, the remainder thin. Pharyngeal glands five pairs of large lobes, the last in VII. Dorsal blood vessel single, continuous onto the pharynx. Dorsoventral commissural vessels in VI-XII; those in IX, anteriorly, slender and arising from the dorsal vessel only; those in XXII forming three pairs of large latero-oesophageal hearts each of which receives a connective from the dorsal vessel and one from a paired circum-oesophageal vessel shortly before this joins a single, midorsal supra-oesophageal vessel which occupies segment IX-XII. Subneural vessel absent.

Oesophagus in V-VII enveloped by the pharyngeal glands and moniliform and extremely thin walled. Similar but not obscured, in VIII and IX, a gizzard being totally absent. In $\mathrm{X}$ expanded and croplike with a pair of circumferential vessels, in XI and XII segmentally dilated and similarly vascularized. In XIII the oesophagus bears a pair of large lateral reniform calciferous glands sessile on the oesophagus over half of its circumference, the two glands merging middorsally and midventrally. The cavity of each gland is occupied by lamellae orientated radially relative to the oesophagus and with their greatest widths longitudinal. Each gland sends an anterior and a posterior calciferous vessel to the dorsal blood vessel. Oesophagus in XIV and XV narrow but still moderately vascular and sending paired vessels to the dorsal vessel. Intestine commencing with abrupt

TABLE 4

\section{INTERSETAL DISTANCES IN SEGMENT XII IN}

\section{Paraplutellus insularis}

\begin{tabular}{lcccccccccccc} 
& \multicolumn{2}{c}{ aa } & \multicolumn{2}{c}{$\mathrm{ab}$} & \multicolumn{2}{c}{$\mathrm{bc}$} & \multicolumn{2}{c}{$\mathrm{cd}$} & \multicolumn{2}{c}{ dd } & dd:u \\
& $\mathrm{mm}$ & $\mathrm{st}$ & $\mathrm{mm}$ & $\mathrm{st}$ & $\mathrm{mm}$ & $\mathrm{st}$ & $\mathrm{mm}$ & $\mathrm{st}$ & $\mathrm{mm}$ & \multicolumn{1}{c}{ st } & \\
holotype & 0.84 & 9.24 & 0.57 & 6.22 & 1.11 & 12.16 & 1.37 & 15.02 & 2.18 & 23.98 & \\
intervals/ab & & 1.49 & & 1.00 & & 1.95 & & 2.41 & & 3.86 & 0.24 \\
paratype & 0.77 & 9.46 & 0.58 & 7.13 & 1.02 & 12.53 & 1.23 & 15.50 & 1.72 & 21.13 & \\
intervals/ab & & 1.33 & & 1.00 & & 1.76 & & 2.17 & & 2.96 & 0.21
\end{tabular}


expansion and narrow oesophageal valve in XVI, typhlosole and muscular thickening absent.

Nephridia stomate vesiculate exonephric holonephridia throughout. The ectal duct of each nephridium entering the side of a large elongate bladder the opposite side of which projects as a wide diverticulum; the diverticulum median if the nephropore is in $b$, lateral if it is in $d$.

Testes and large iridescent funnels free in $\mathrm{X}$ and XI; seminal vesicles elongate, racemose, in IX and XII. Prostates tubular, restricted to XVIII in which the glands run laterally and then for an equal distance medianly; the duct tortuous and about half as long, its ental half narrow, its ectal half wide and with a strong muscular sheen. Vasa deferentia double on each side, joining the prostate glands ental of the ducts. Penial setae present in XVIII; whiplike, with moderately stout basal portion and longer, slender undulating region which bears sparsely scattered inconspicuous teeth or spines; length ca. $1 \mathrm{~mm}$ (uncertain owing to fragmentation) width of shaft $8 \mu$; greatest width of base (terminally) $12 \mu$.

Ovaries (consisting of many egg-strings) and moderate sized funnels in XIII. Ovisacs absent. Spermathecae five pairs, discharging anteriorly in their segments; each with an ovoid ampulla, somewhat longer narrow cylindrical duct and a small clavate sperm-filled lateral diverticulum joining the duct slightly ectal of its middle. Length of right spermatheca of IX $=1.2 \mathrm{~mm}$, ratio total length: length of duct $=$ $2 \cdot 1$; ratio total length: length of diverticulum $=2 \cdot 7$.

Material examined: Two clitellate specimens, here designated holotype and paratype (new registration numbers G1543 and G1544 respectively); collector?, Baldwin Spencer collection. The sample includes two labels, both giving the locality as Lord Howe Island, one bearing the date Jan. 1903 but no registration number, the other Jan. 1906 and the number G416. With the two syntypes is a specimen of a large perichaetine worm.

\section{Discussion}

Paraplutellus and Simsia, in having male and prostatic pores restricted to segment XVIII and holonephridia, are placeable in a Perionyxgroup which is composed of the genera $\mathrm{Pe}$ rionyx Perrier, 1872 , Comarodrilus Stephenson, 1915, Diporochaeta* Beddard, 1890, Diplotrema (part, New Caledonian species only) Spencer, 1900, Fletcherodrilus* Michaelsen, 1891, Heteroporodrilus* Jamieson, 1970, Plutellus* Perrier, 1873; Pontodrilus* Perrier, 1874; Pseudoperichaeta* Jamieson, 1970 and Woodwardiella* Stephenson, 1925.

Spenceriella belongs to a distinct group of megascolecid genera which are meronephric with (in each prostate segment) an exonephric, stomate meronephridium median to astomate micromeronephridia. This Dichogaster-group (Jamieson 1971a) contains many genera, notably Dichogaster Beddard, 1888, Didymogaster* Fletcher, 1887a, Digaster* Perrier, 1872, Eutyphoeus Michaelsen, 1900, Megascolides* McCoy, 1878, Notoscolex* Fletcher, 1887 a, s. str. Jamieson 1971c, and Spenceriella* Michaelsen, 1907 (typical part).

* Genera indigenous in Australia.

\section{Acknowledgements}

The author thanks Dr. B. J. Smith of the National Museum of Victoria and Miss E. Pope of the Australian Museum, Sydney, for arranging loans from the Spencer and Fletcher collections and for their kind co-operation in other respects. Miss Carden Horan is thanked for descriptions of nephridia. This work was made possible by an A.R.G.C. grant.

\section{References}

BAIRD, W., 1871. Megascolex antarctica, an earthworm from New Zealand. Proc. Linn. Soc. Lond.
11: 96 .

BEDDARD, F. E., 1889. On certain points in the structure of Urochaeta E.P., and Dichogaster, nov. gen., with further remarks on the nephridia of earthworms. Quart. J1 microsc. Sci. (n,s.) 29: 235-282.

cies of Perichaeta and 1890 . Observations upon an American species of Perichaeta and upon some other members of the genus. Proc, zool. Soc. Lond. 1890: 52-69. chaeta. Oxford.

BENHAM, W. B., 1906. Earthworms from Little Barrier Island. Trans. N.Z. Inst. 38: 248-256.

Fletcher, J. J., 1887 a. Notes on Australian earthworms. Pt. 1. Proc. Linn. Soc. N.S.W. 1 (2) 1886: 
1888. Notes on Australian earthworms. Pt, 4. Proc. Linn. Soc. N.S.W., 2 (2) 1887: 601-620. . 1889. Notes on Australian earthworms. Pt. 5. Proc. Linn. Soc. N.S.W., 3 (2) 1888: 15211558.

JAMIESON, B. G. M., 1970. A revision of the Australian earthworm genus Woodwardiella with descriptions of two new genera (Megascolecidae: Oligochaeta) J. Zool. Lond. 162: 99-144.

, 1971a. A review of the megascolecoid earthworm genera (Oligochaeta) of Australia. Part I-Reclassification and checklist of the megascolecoid genera of the world. 82(6): 75-86.

- 1971b. Descriptions of the type-species of the earthworm genera Plutellus and Digaster (Megascolecidae: Oligochaeta). Mem. Mus. natn. Hist. nat., Paris, ser. 2, 42(6): 1300-1310.

, 1971c. Redescription of the type-species of the earthworm genus Notoscolex (Megascolecidae: Oligochaeta). J. nat. Hist., London (In press).

Jensz, R. L. and SMIth, B. J., 1969. Catalogue of Baldwin Spencer earthworm types in the National Museum of Victoria, Australia. Mem. natn. Mus. Vict. 29: 85-110.

KikKaWA, J. and Pearse, K., 1969. Geographical distribution of land birds in Australia-a numerical analysis. Aust. J. Zool. 17: 821-40.

LEE, K. E., 1959. The earthworm fauna of New Zealand. Bull. N.Z. Dep. scient. ind. Res. 130: 1-486.

- 1962. New Zealand earthworms in the collections of the British Museum (Natural History). Trans. R. Soc. N.Z. 2 (20): 169-180.

McCoy, F., 1878. Megascolides. Prodr. zool. Vict. 1: 21-25.

MACNAB, J. A. and McKey-Fender, D., 1953. Description of two new species of Plutellus (Oligochaeta, Megascolecidae). Wasmann J. Biol. 10 (3): 313-354.

, 1960. Subspecific variation in Plutellus davisi (Oligochaeta, Megascolecidae) N.W. Sci. 34 (4): 127-133.

MichaelseN, W., 1891. Oligochaeten des Naturhistorischen Museums in Hamburg, IV. Jb. hamb. wiss. Anst. 8: 299-340.

, 1900. Das Tierreich. 10. Vermes, Oligochaeta. Berlin.
, 1907. Oligochaeta in Die Fauna Südwest-
Australiens. 1 (2): 117-232. Jena.

Perrier, E., 1872. Récherches pour servir a l'histoire des lombriciens terrestres. Nouv. Archs Mus. Hist. nat., Paris 8: 19-197.

, 1873. Etude sur un genre nouveau de lombriciens (Genre Plutellus E.P.). Archs Zool. exp. gen. 2: 245-268.

- 1874. Sur les lombriciens exotiques des genres Urochaeta et Perichaeta. Cr. hebd. Seanc. Acad. Sci., Paris 78: 814-817.

SPENCER, W. B., 1892a. Preliminary description of Victorian earthworms. Pt. 1. The genera Cryptodrilus and Megascolides. Proc. R. Soc. Vict. 4: 130-156.

- 1892b. Preliminary notice of Victorian earthworms. Pt. 2. The genus Perichaeta. Proc. R. Soc. Vict. 5: 1-26.

, 1900. Further descriptions of Australian earthworms, Pt. 1. Proc. R. Soc. Vict., 13: 29-67.

Standard, J. C., 1967. Islands and seamounts to the east of Australia. Aust. nat. Hist. 15 (12): 382387.

StePHENSON, J., 1915. On some Indian Oligochaeta mainly from southern India and Ceylon. Mem. Ind. Mus. 6: 35-108.

1925. Oligochaeta from various regions, including those collected by the Mount Everest Expedition, 1924. Proc. zool. Soc. Lond. pp. 879 907.

, 1930. The Oligochaeta. Oxford.

SWEET, G., 1900. On the structure of the spermiducal glands and associated parts in Australian earthworms. J. Linn. Soc. Zool. 28 (180): 109-139.

Templeton, R., 1844. Description of Megascolex caeruleus. Proc, zool. Soc. Lond. 12: 89-90.

\section{LIST OF ABBREVIATIONS USED IN THE ILLUSTRATIONS}

ca.g., calciferous glands; ca.v., calciferous vessel; d.v., dorsal vessel; $\$$, female pore; g.m., accessory genital marking; int., intestine; 1.g.m., lateral accessory genital marking; lo, latero-oesophageal vessel; lo.h., latero-oesophageal heart; $\delta$, male pore; m.g.m., median accessory genital marking; np., nephropore; oe, oesophagus; pr.d., prostate duct; pr.g., glandular part of prostate; sp.amp., spermathecal ampulla; sp.d., spermathecal duct; sp.div., spermathecal diverticulum; sp.p, spermathecal pore; v.d., vas deferens. 


\section{$2 \mathrm{BHL}$ Biodiversity Heritage Library}

Jamieson, B G M. 1972. "The australian earthworm genus Spenceriella and description of two new genera (Megascolecidae: Oligochaeta)." Memoirs of the National Museum of Victoria 33, 73-87.

View This Item Online: https://www.biodiversitylibrary.org/item/120609

Permalink: https://www.biodiversitylibrary.org/partpdf/50072

\section{Holding Institution}

Museums Victoria

\section{Sponsored by}

Atlas of Living Australia

\section{Copyright \& Reuse}

Copyright Status: Permissions to digitize granted by rights holder.

This document was created from content at the Biodiversity Heritage Library, the world's largest open access digital library for biodiversity literature and archives. Visit BHL at https://www.biodiversitylibrary.org. 